\title{
O MODELO DE VIDA ALIENANTE DA “SOCIEDADE DO CONSUMO”
}

\author{
THE ALIENATING MODEL OF LIFE IN “CONSUMER SOCIETY”
}

\section{EL MODELO DE VIDA ALIENANTE EN "SOCIEDAD DE CONSUMO”}

\author{
Atilio Marchesini Jr. \\ Mestre em Geografia - Universidade Estadual de Campinas - UNICAMP \\ Rua da Penha, $n^{\circ}$ 786, Bairro Santo Antonio - Itapira - São Paulo \\ junior.atilio@yahoo.com.br
}

\section{Resumo}

Nesse artigo propusemos uma reflexão sobre o significado que o consumo passa a representar na vida de grande parte da sociedade, uma condição "sine qua non" para a felicidade, e como o sistema capitalista, a globalização e o marketing tornam-se grandes estimulantes desse processo. A sociedade se torna alienada por tudo que a envolve, o consumidor passa a alimentar-se de parcialidades, baseando-se em satisfações limitadas e não usufruindo do seu direito de debater assuntos relacionados às políticas públicas, voto e ações públicas ou privadas (SANTOS, 1998). A relação da "Sociedade do Consumo" e as mais variadas teorias sobre a alienação social são de extrema relevância para a análise urbana e social no final do século XX e início do século XXI.

Palavras-Chave: Consumo, Alienação, Capitalismo, Marketing e Sociedade.

\begin{abstract}
In this article we propose a reflection on the meaning that the consumer comes to represent a large part in the life of society, a condition "sine qua non" for happiness, and how the capitalist system, globalization and marketing become major stimulants of this process. Society become alienated from everything that surrounds it, the consumer starts to feed on the bias, based on limited satisfactions and not taking advantage of their right to discuss matters related public policy, voting and public or private actions (Santos, 1998). The relationship of "consumer society" and the various theories on social alienation are very important for the urban and social analysis in the last century and beginning XXI century.
\end{abstract}

Keywords: Consumption, Disposal, Capitalism, Marketing and Society.

\section{Resumen}

En este artículo proponemos una reflexión sobre el sentido de que el consumidor viene a representar un papel importante en la vida de la sociedad, una condición "sine que non" para la felicidad, y como el sistema capitalista, la globalización y la propaganda hacer en fuertes estímulos de este proceso. La sociedade se aliena de todo aquello que lo rodea, el consumidor se alimenta de la parcialidad, en base a las satisfacciones limitadas y no aprovechando de su derecho a tratar asuntos relacionados con las políticas públicas de votación, y las acciones públicas e privadas (Santos, 1998). La relación de "sociedad 
de consumo" y las diversas teorias sobre la alienación son muy importantes para el análisis urbano y social de finales del siglo XX, y princípios del siglo XXI.

Palabras clave: Consumo, Alienación, Capitalismo, Propaganda y Sociedad

\section{Introdução}

O presente artigo busca fazer uma análise entre a sociedade atual, caracterizada pelas marcas do capitalismo, e o processo de alienação social, causado direta ou indiretamente pelo mesmo capitalismo responsável por direcionar a vida dessa sociedade. A marca principal que os indivíduos revelam é a do consumismo, que compõe o capitalismo globalizado vivido no final do século XX e início do século XXI.

A melhor definição para pensar a sociedade atual é a de uma "Sociedade de Consumidores", entretanto, não falamos do consumo natural e necessário para a sobrevivência, mas aquele consumo desnecessário, criado pela publicidade, indicado por símbolos e avalizado pela moda e pela padronização que o capitalismo propõe. A sociedade consumista se relaciona a um novo modelo de socialização, baseado na perda de valores essenciais para o ser humano real, ou seja, a valorização de sentimentos e ideais que sejam importantes para a vida em grupo, em família, enfim, em sociedade.

Grande parte das pessoas, na sua vida rotineira e descontraída, não se dá conta de que vive numa sociedade consumista, cheia de anacronismos, ou seja, uma sociedade com problemas intrínsecos a sua condição capitalista. Sociedade que é vítima de si própria e incapaz de melhorar por seu próprio esforço, e não percebem que são responsáveis, de alguma forma, por crises econômicas, sociais, ou ainda desastres ecológicos universais. A ordem do dia é comprar cada vez mais, até esgotar os proventos, comprar com crédito, comprar tudo o que for possível, mesmo o que não seja necessário, e são os próprios que compram que se iludem, que criam as suas próprias falsas necessidades, numa sociedade que pretende ter o máximo, seja do que for, especialmente ter cada vez mais que o vizinho do lado, ainda que outros vizinhos menos afortunados vegetem na miséria mais incrível. Essa condição nos leva a análise promovida por inúmeros autores no último século, como Karl Marx , Milton Santos, István Mészáros, entre outros, a "Teoria da Alienação", que busca entender os efeitos 
maléficos do capitalismo, e hoje da globalização, sobre a cada vez mais fragilizada e influenciável sociedade mundial.

Procuramos analisar a alienação sobre vários aspectos, baseando-se na obra “A Teoria da Alienação em Marx”, de István Mészáros, que analisa a teoria proposta por Marx, relacionando com o mundo atual e as conseqüências avanço capitalista. Mészáros (2006), desenvolve o conceito de alienação como uma condição de "vendabilidade" do ser humano, ou seja, as novas necessidades e mercadorias produzidas de forma desconcertante e a revelia, tornam os indivíduos cada vez mais individualizados e até egoístas, o que nos ajuda no entendimento da sociedade atual.

É evidente que a humanidade seria muito melhor, se trocasse um pouco deste consumismo endeusado e até obrigatório, esta ganância feita virtude e ensinada automaticamente desde o berço, por um pouco mais de solidariedade e urbanidade entre os seres humanos. Para isso individualismos, simulacros e moda deveriam ser postos de lado e transformados em comunhão e integração de todos por uma vida mais digna e igualitária entre todos os seres humanos do planeta.

\section{A Sociedade do Consumo no século XXI}

Os mais variados empreendimentos comerciais que surgem no século $\mathrm{XX}$ envoltos por um momento do capitalismo em que o consumo é parte central da valorização do capital, criam uma sociedade direcionada a consumir indiscriminadamente, podendo ser denominada de "Sociedade do Consumo" (BAUMAN, 2008).

Entendemos que a análise do consumo permite uma melhor compreensão do espaço urbano e social, na medida em que comércio, cidade, sociedade e meio ambiente são elementos que se completam. Consequentemente, o processo de produção e comercialização intenso implica em consumo, por uma sociedade cada vez mais acostumada e influenciada pelo ato de comprar. Podemos afirmar, dessa forma, que o consumidor torna-se também uma mercadoria, não sendo mais somente o produtor, mas sim uma mercadoria que consome mercadorias, materiais e imateriais. (SANTOS, 2003). O consumo vem crescendo freneticamente no mundo contemporâneo. Em 2006, pessoas no mundo todo gastaram US\$ 30,5 trilhões em bens e serviços (em dólares de 
2008). Em 1996, esse número foi de US\$ 23,9 trilhões e em 1960 a humanidade consumiu o equivalente a US\$ 4,9 trilhões. Só em 2008, pessoas no mundo todo compraram 68 milhões de veículos, 85 milhões de geladeiras, 297 milhões de computadores e 1,2 bilhão de telefones móveis (celulares), segundo dados do Instituto Akatu.

$\mathrm{Na}$ atualidade, vivemos um período em que há um processo que vamos denominar de "criação de necessidades", quando o capitalismo traz à sociedade uma variedade cada vez maior de produtos que passam a ser consumidos por todo o globo e, em alguns países, principalmente nos mais avançados, de forma desenfreada. Vivemos em um mundo em que o consumo faz parte da natureza do ser humano, já que é preciso consumir para obter o que é necessário para nossa sobrevivência, mas nota-se que as necessidades acabam por ser criadas ou modificadas de acordo com os interesses do capital.

Necessidade é conceito relativo. As necessidades não são constantes porque elas são categorias da consciência humana desde que a sociedade se transforma, a consciência da necessidade transforma-se também. O problema é definir exatamente em que a necessidade é relativa, e entender como as necessidades surgem. As necessidades por serem definidas a respeito de um número de diferentes categorias de atividade - permanecendo estas completamente constantes no tempo (alimento, habitação, cuidados médicos, educação, serviço social e ambiental, bens de consumo, oportunidades de lazer, amenidades de vizinhança, facilidades de transporte). (HARVEY, 1980, p. 87)

Os cidadãos são transformados em simples consumidores, que são movidos de acordo com os interesses do capital, que imputam ao indivíduo o imediatismo, ou seja, a felicidade está contida no consumir nesse instante, com funcionalidade e rapidez, o que transforma em prazer $\mathrm{o}$ ato de consumir, e promove o aparecimento de "novas necessidades" a todo instante.

Depois de estarem preenchidas as necessidades básicas ou primárias, a evolução da sociedade de consumo trouxe o desenvolvimento de necessidades no domínio do lazer e da cultura, o consumo dos sentidos associados a objectos e situações. (...) Com o avanço da modernidade e os aumentos da complexidade social, o consumo passa a desempenhar um papel decisivo na construção das identidades. (BARATA SALGUEIRO, 2006, p. 18)

Padilha (2006) reflete a situação avaliando que na atualidade as relações humanas são sempre mediatizadas por coisas, onde os sentimentos devem ser 
materializados, para que haja realmente felicidade para os cidadãos. É um processo, de fato, em que marketing e a propaganda trabalham com o imaginário do ser humano criando e recriando conceitos e significados relacionados ao que deve ser necessário ao consumo. Pintaudi (1989, p. 06) resume bem tal condição: “O psíquico do ser humano é muito bem trabalhado pela propaganda".

O exemplo do "vizinho rico" é clássico, onde o mesmo sempre aparece em melhor condição de vida, como o vitorioso, ostentando mais produtos. Exemplo disso é possível ver no filme "Amor por contrato" de 2010, uma comédia que reflete uma família aparentemente perfeita, que se muda para um novo bairro e imediatamente passa a ser o centro das atenções, sempre pelos melhores motivos, mas a família perfeita na verdade é uma farsa, parte de uma campanha de marketing de uma empresa, responsável pela divulgação de inúmeros produtos luxuosos a famílias de todo o mundo, criando necessidades irrelevantes para a vida dos vizinhos que passam a ambicionar os "vizinhos ricos e felizes". Entendemos que o indivíduo é condicionado ao consumo, criando necessidades que, na verdade, são impostas pela mídia e pelo marketing, como coloca Santos (2003, p. 127) “consumir não mais por necessidade, mas por ansiedade”.

Então, a publicidade - âncora da sociedade do consumo - baseia-se em falsas ideias que vendem objetos mutáveis e consumíveis massivamente como se fossem únicos. E na maioria das vezes, como se fossem a fórmula mágica para a realização de um sonho. (PADILHA, 2006, p. 101)

Dessa forma, na atual conjuntura do sistema capitalista onde o processo de globalização atua por todo o planeta, nota-se mudanças na sociedade que passa a tratar o ato de consumir de maneira cada vez mais alienada. $\mathrm{O}$ momento do consumo vai adquirindo maior importância, não somente para o que é básico, mas também para o que é "supérfluo". Santos (2007, p. 49) afirma de forma categórica “[...] vivemos cercados, por todos os lados, por esse sistema ideológico tecido ao redor do consumo e da informação ideologizados". Assim, voltamos a concordar com Bauman (2008) ao denominar a sociedade atual como a "Sociedade do Consumo", que tem como valor mais característico e supremo ter uma vida feliz, e isso se baseia em grande parte no consumir. Como o mesmo Bauman (2008) coloca, consumir não é sinônimo de ter felicidade, visto que pesquisas, em países em que o capitalismo está mais desenvolvido, 
não indicam maior felicidade para as pessoas em relação àquelas que vivem em países pobres.

Analisamos a "Sociedade do Consumo" baseando-se nas seguintes características:

- Para a maioria dos bens, a sua oferta excede a procura, levando a que as empresas recorram a estratégias de marketing agressivas e sedutoras que induzem o consumidor a consumir, permitindo-lhes escoar a produção.

- Alguns produtos e serviços estão normatizados, os seus métodos de fabricação baseiam-se na produção em série e recorre-se a estratégias de obsolescência programada que permite o escoamento permanente dos produtos e serviços.

- Os padrões de consumo estão cada vez mais massificados, assumindo as características da moda, apenas como forma de integração social.

- Existe uma tendência para o consumismo (um tipo de consumo impulsivo, descontrolado, irresponsável e muitas vezes irracional), justamente pelo processo de valorização do capital pela publicidade e marketing.

O fetichismo e o consumismo tomam conta do processo de trocas comerciais, onde a propaganda e a comercialização acabam por reduzir os vestígios de construção e produção das verdadeiras imagens do que é consumido. (HARVEY, 2009). Assim, a expressão "Sociedade de Consumo" refere-se a uma sociedade atual, que vive a “intensificação do moderno" (RODRIGUES, 1998, p. 08), onde o mercado tem produtos e padrões de consumo cada vez mais normatizados, e que se renovam a uma velocidade extrema. $\mathrm{O}$ excesso de oferta, aliado a uma enorme profusão de bens colocados no mercado, levou ao desenvolvimento de estratégias de marketing extremamente agressivas, que procuram impor tal padrão de consumo, aliado ao que chamamos de obsolescência programada, que é o nome dado a vida curta de um bem ou produto projetado, de forma que sua durabilidade ou funcionamento se dê apenas por um período reduzido. É um processo de certa forma característico do capitalismo na segunda metade do século XX, que podemos chamar também de "descartalização", o que acaba causando grandes danos ao meio ambiente. Tal processo faz parte de uma estratégia de mercado que visa garantir um consumo constante através da insatisfação, 
de forma que os produtos que satisfazem as necessidades daqueles que os compram parem de funcionar, tendo que ser obrigatoriamente substituídos de tempos em tempos por mais modernos.

\begin{abstract}
"Mas é no momento presente que são produzidas novas e novas mercadorias destinadas a um mercado de consumo comum. Mercadorias cada vez mais rapidamente descartadas, pois "nada parece durável". Assim, constitui-se a sociedade do descartável, pois o produzido hoje será velho amanhã e a sociedade é também descartável, pois seus problemas só seriam "resolvidos" no futuro." (RODRIGUES, 1998, p. 08)
\end{abstract}

Em 2007, o brasileiro trocava de celular, em média, a cada dois anos, e hoje, troca a cada 1,3 ano. As companhias induzem a troca e os consumidores compram, e as pequenas modificações que são feitas nos aparelhos não são realmente relevantes, mas o consumidor as considera importantes e acaba fazendo a troca. $\mathrm{O}$ resultado de tanto desperdício é que o uso dos recursos naturais está ultrapassando a capacidade que o planeta tem de provê-los. Entre 1950 e 2005, por exemplo, a produção de metais cresceu seis vezes, a de petróleo, oito, e o consumo de gás natural, 14 vezes. Atualmente são extraídas 60 bilhões de toneladas de recursos anualmente, cerca de $50 \%$ a mais do que há apenas 30 anos. O europeu médio usa 43 quilos de recursos diariamente, e o americano médio, 88 quilos. O mundo extrai, hoje, o equivalente a 112 edifícios "Empire State" da Terra a cada dia.

Podemos avaliar o consumismo baseado em frentes diversas, relacionado à velocidade da renovação dos produtos, com linhas e modelos atualizados em poucos meses, a força do marketing ampliado e estimulado no capitalismo atual, e também a produção de bens que duram menos, o que força o consumidor a trocá-lo constantemente. A questão do consumismo vem se tornando cada vez mais importante, o que permite uma indagação crítica a respeito de como o planeta pode gerar tudo o que é necessário para a produção cada vez maior de variados setores industriais. Com o consumo em expansão, aliado ao processo de obsolescência programada, o consumo de matéria prima retirada do meio ambiente é cada vez maior.

Rodrigues (1998, p. 13) comenta que "Cantada em prosa e verso a 'natureza' está sendo destruída." Frisa que a natureza vem sendo extremamente afetada pelo modelo de sociedade que se criou com o capitalismo no século XX/XXI, pois a produção é cada vez maior, o que gera um consumo intenso de matérias primas e fontes de energia oferecidos pela natureza. O consumo também pode ser exercido através do 
lazer e do turismo, onde a sociedade se apropria de espaços naturais transformando-os em verdadeiras mercadorias.

\begin{abstract}
Parece que o responsável pela poluição e pelo aumento da temperatura - o efeito estufa - é o automóvel em si, ou seu proprietário, e não a produção de mercadorias, o desenvolvimento científico-tecnológico que "criou" o automóvel. Parece, também, que o desenvolvimento científico-tecnológico não faz parte da produção socioespacial. Embora já esteja demonstrado, em larga medida, que a produção de mercadorias e a produção da segunda natureza sejam "responsabilidade" do modo industrial de produzir, esta está simbolicamente deslocada para os indivíduos consumidores. (RODRIGUES, 1998, p. 31)
\end{abstract}

A "sociedade do consumo" cada vez mais participa do processo indireto, ou porque não dizer direto, de degradação do meio ambiente, a partir de um aumento cada vez maior do processo produtivo, em função das inúmeras novas "necessidades" criadas a todo instante. A sociedade cada vez mais consome o chamado espaço natural, que vem sendo, principalmente nas grandes cidades, espaços cada vez mais raros e, portanto, valorizados.

\title{
Alienação e Sociedade
}

A sociedade do século XXI, caracterizada pelo consumo, desenvolveu uma condição alienante em relação a situações recorrentes na vida urbana atual. $\mathrm{O}$ consumo dá identidade às pessoas, mas por outro lado promove a massificação das ideias, e aglutina sobre os mesmos padrões a vida dos indivíduos. A moda dita o ritmo da vida e enfraquece o consenso coletivo de cidadania e bem estar social de todos.

No mundo contemporâneo a sociedade vem sendo reinventada, ou seja, os padrões de vivência mudam com o passar do tempo, as condições impostas pela tecnologia e pelo desenvolvimento das cidades são diferentes do passado, mas por outro lado, é anexo a vivência das novas gerações, desde muito jovens, o ideal da competitividade exacerbada, o ideal da moda, o ideal capitalista, de forma que vemos o surgimento de jovens doutrinados por padrões pré-determinados, como um exército de consumo e individualismo buscando conseguir "qualquer coisa a qualquer custo". Santos (2007, p. 48) analisa perfeitamente a influência da moda na sociedade: 
"Não é a mudança para atingir o futuro, mas para permanecer no passado. A moda é desses artifícios com o qual as coisas ficam as mesmas, embora aparentando uma transformação. A moda é a manivela do consumo, pela criação de novos objetos que se impõem ao indivíduo."

É uma nova modernidade, o desmantelamento progressivo de certas representações sociais, de modo que, fora maior juízo de valor, os poderes de derretimento próprios da modernidade mudam de mãos (BAUMAN, 2001). Ou seja, tais poderes "passam do sistema para a sociedade e da política para as políticas da vida" (BAUMAN, 2001, p. 14).

O consumo direciona a vida da sociedade, como discorre Santos (2007, p. 48) “O poder do consumo é contagiante, e sua capacidade de alienação é tão forte que sua exclusão atribui às pessoas a condição de alienados. Daí sua força e o seu papel perversamente motor na sociedade atual”. É o processo de glorificação do consumo, onde a individualidade torna-se a principal característica do ser humano, e a cidadania se perde ou muda de características. "O consumo contribui ao aniquilamento da personalidade, sem a qual o homem não se reconhece como distinto, a partir da igualdade de todos".” (SANTOS, 2007,p. 49)

A alienação da sociedade é discutida e estudada por inúmeros autores relevantes, por um longo período, o que proporciona visões diversas sobre o assunto. É considerável avaliar algumas dessas opiniões, pela qual a palavra alienação vem sendo usada segundo as mais variadas acepções. Navarro de Brito (1977, p. 344) traduz alienação como "o processo de fragmentação do conhecimento e, consequentemente, distorção da realidade". (NAVARRO DE BRITO, 1977, p. 344). Já Agnes Heller (1982, p. 55), analisa como a "cisão entre a essência do homem e sua existência $|. .$.$| resultado$ do desenvolvimento das potencialidades do homem em detrimento de sua essência". (Heller, 1982. p. 55). Perroux (1970, p. 76) é mais complexo, e define alienação mais intensamente:

\footnotetext{
"A alienação é a alteridade imposta ao homem existente concreto, quando ele é privado da consciência de sua decisão autônoma. Ele é reificado como um cadáver ou como um escravo -, duas maneiras de ser coisa |.... A alienação é como o sono; ela é heteronímia. A existência total pode ser "alienada" ou se "alienar" diante do corpo-coisa. Na sociedade, o homem é "alienado" ou "se aliena", além do aparelho, a alguém que dirige o aparelho ou que dele tira vantagem. Para desalienar, é necessário compreender a estrutura do aparelho e a estrutura dos poderes intersubjetivos a que serve"
} 
De qualquer forma todos refletem a submissão do ser humano para o consumo, ou seja, os produtos são criados para a simples vaidade de um contra o outro, é a busca incessante pelas "coisas". A força da publicidade busca atingir cada um em função dos outros, por suas vontades e fantasias de prestígio social. Ela nunca se dirige a uma única pessoa, procurando suas maiores motivações, e relacionando isso com o grupo que o envolve, hierarquizada no processo de leitura e de interpretação, no processo de valorização que ela instala (BAUDRILLARD, 1970). Afinal, no processo alienado de uma pessoa a relação que ela tem com um objetivo não existe mais, a necessidade passa a ter uma conotação abstrata e muitas vezes insignificante, e a opinião dos "outros", ou da maioria, muitas vezes torna-se mais importante e imprescindível.

O consumo tem sua própria força, e cada vez ela é maior, mas a força do consumidor pode ainda ser mais forte. Assim acreditamos que "onde o indivíduo também é cidadão, pode desafiar os mandamentos do mercado, tornando-se um consumidor imperfeito, porque é insubmisso a certas regras impostas de fora dele mesmo. Onde não há o cidadão, há o consumidor mais-que-perfeito" (SANTOS, 2007, p.57).

Mas é interessante que as maiores possibilidades de consumo estão diretamente ligadas as classes sociais mais elevadas, ou seja, é claro que a classe média e alta tem um poder de consumo maior, e com isso mais influenciáveis pela massificação do consumo, pelo marketing, etc. Nas cidades grandes tal condição é ainda mais fulgente, (...) "a dificuldade e mesmo a impossibilidade de se tornar um assalariado, graças às condições ao trabalho com a progressão atual do sistema técnicoprodutivo, subtrai dos mais pobres a possibilidade de ser um consumidor pleno" (SANTOS, 2007, p. 85). É por isso que concordamos com Santos (2007, p. 86) quando expõe que no círculo inferior de economia a exposição e risco de se tornar um "ser alienado" é bem menor para o indivíduo.

"Eles sabem que de nada adianta imaginar que um dia alcançarão os tesouros que abarrotam as casas dos ricos e da classe média. O que eles aspiram sobretudo é alcançar, pelo menos, aqueles bens e serviços que tornam a vida mais digna. E é diante da consciência das impossibilidades de atingir mesmo aquele mínimo essencial que os pobres descobrem o seu verdadeiro lugar, na cidade e no mundo, isto é, sua posição social." (SANTOS, 2007, p. 86) 


\section{A Teoria de Marx}

O estímulo ao consumo gerado pelo marketing, dentro de um empreendimento comercial, na rua ou televisão, provoca no consumidor um processo de "consumir por consumir". Ou seja, o ato de comprar pela necessidade que realmente temos de alguma coisa é substituído por comprar apenas pelo prazer, pela satisfação de ter algo que outro indivíduo não tem, ou por algo que todos tem e você ainda não, o que também o diferencia. Esta condição, extremamente alienante na sociedade capitalista, mostra que o consumo ganha características de solução para tristezas e decepções da vida cotidiana.

\footnotetext{
"Numa sociedade tornada competitiva pelos valores que erigiu como dogmas, o consumo é verdadeiro ópio, cujos templos modernos são os shopping centers e os supermercados, aliás, construídos à feição das catedrais. O poder do consumo é contagiante, e sua capacidade de alienação é tão forte que sua exclusão atribui às pessoas a condição de alienados. Daí a sua força e o seu papel perversamente motor na sociedade atual." (SANTOS, 1998, p. 34).
}

A sociedade consumista é a sociedade que aprende e amplia diariamente o condicionamento social do consumo e se relaciona a um novo modelo de socialização, junto à emergência de forças produtivas inovadoras e de um sistema econômico monopolista e de alta produtividade (BAUDRILLARD, 1970). O consumidor passa a alimentar-se de parcialidades, baseando-se em satisfações limitadas e não usufruindo do seu direito de debater assuntos relacionados às políticas públicas, voto e ações públicas ou privadas (SANTOS, 1998). O consumo passa a ser glorificado, como define muito bem Santos (1998) mostrando que o mesmo gera uma diminuição de sensibilidades importantes ao ser humano, alimentando um individualismo sem fronteiras, reduzindo ou aniquilando a personalidade do indivíduo.

A base para o entendimento do conceito de alienação que pretendemos utilizar é a teoria de alienação em Marx, uma das mais importantes contribuições deixadas para a sociedade feita pelo autor. Marx foi fortemente influenciado por Feuerbach e Hegel em seus pensamentos (MÉSZÁROS, 2006), e a discussão do tema é analisada por István Mészáros em sua obra “A Teoria da Alienação em Marx” de forma distinta e significativa: 
"A alienação caracteriza-se, portanto, pela extensão universal da "vendabilidade" (isto é, a transformação de tudo em mercadoria); pela conversão dos seres humanos em "coisas", para que eles possam aparecer como mercadorias no mercado (em outras palavras: a "reificação" das relações humanas); e pela fragmentação do corpo social em "indivíduos isolados", que perseguem seus próprios objetivos limitados, particularistas, "em servidão à necessidade egoísta", fazendo de seu egoísmo uma virtude em seu culto da privacidade.” (MÉSZÁROS, p. 39, 2006)

Não temos a pretensão de uma avaliação profunda da teoria de Marx, visto que sua complexidade é imensa, e o tema passa por constantes análises. A avaliação dos problemas são frequentemente retomados, em níveis de complexidade cada vez mais altos, de acordo com o aparecimento e a crescente concretização da visão de Marx como um todo, o que transmite uma grande dificuldade para os leitores e estudiosos (MÉSZÁROS, 2006).

Marx avalia o histórico e a estrutura da problemática da alienação, em relação às complexidades da vida real e influencia nas variadas formas de pensamento. Marx pensa a teoria da alienação da seguinte forma:

1- As manifestações da auto-alienação do trabalho na realidade, juntamente com as várias institucionalizações, reificações e mediações envolvidas nessa auto-alienação prática, isto é, trabalho assalariado, propriedade privada, intercâmbio, dinheiro, renda, lucro, valor, etc, etc.;

2- Os reflexos dessas alienações por intermédio da religião, da filosofia, do direito, da economia política, da arte, da ciência "abstratamente material" etc;

3- Os intercâmbios e reciprocidades entre (1) e (2); pois "os deuses são, originariamente, não a causa, mas o efeito do erro do entendimento humano. Mais tarde essa relação se transforma em ação recíproca";

4- O dinamismo interno de qualquer fenômeno particular, ou campo de investigação, em seu desenvolvimento de uma complexidade menor para uma maior;

5- As inter-relações estruturais dos vários fenômenos sociais (das quais a reciprocidade entre 1 e 2 é apenas um tipo específico), bem como a gênese histórica e a renovada transformação dialética de todo o sistema de interrelações múltiplas;

6- Uma complicação adicional está no fato de que Marx analisa as teorias em seu contexto histórico concreto, além de investigar as relações estruturais de umas com as outras em cada período particular (por exemplo, Adam Smith economista político em comparação com Adam Smith filósofo moral; ao mesmo tempo, os tipos de respostas dadas por ele - tanto como um economista quanto como um moralista - em relação ao desenvolvimento do capitalismo em geral). (MÉSZÁROS, 2006, p.96)

Conforme apresentado por Mészáros (2006), Marx procura desenvolver sua teoria mais do que sobre uma perspectiva filosófica, mas principalmente sobre uma 
perspectiva prática e concreta. Marx analisa o homem $(\mathrm{H})$, a natureza $(\mathrm{N})$ e a indústria (I) a partir de uma interação tríplice entre as partes.

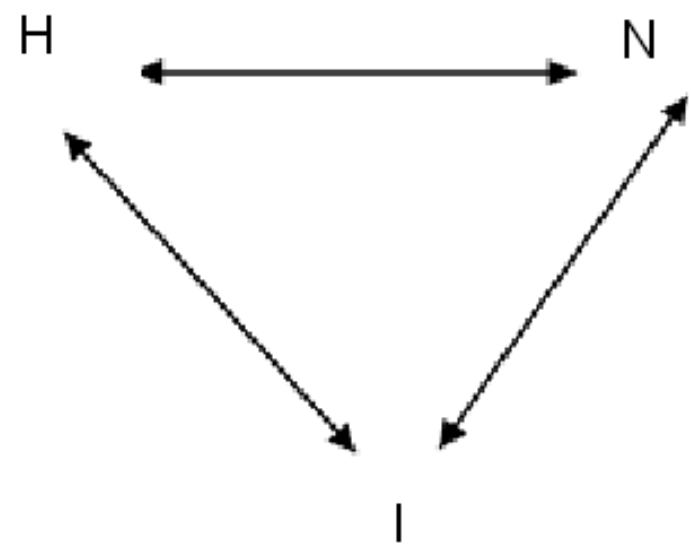

Figura 1: Tríplice Interação de Marx Fonte: MÉSZÁROS, p. 100, 2006. Org. Marchesini Jr. A.

Os termos que Marx utiliza e fundamentam sua teoria, o "homem" $(\mathrm{H})$, a "natureza" $(\mathrm{N})$ e a "indústria" ou "atividade produtiva" (I), se inter-relacionam a todo instante, em todos os sentidos, e esse processo tem uma forte influência na vida da sociedade desde a Revolução Industrial. A "indústria" é ao mesmo tempo a causa da crescente complexidade da sociedade humana, que vem criar novas necessidades, ao mesmo tempo em que satisfaz outras mais antigas. É o conceito de produção de novas necessidades para a sociedade, e o meio de afirmar a supremacia do homem - como "ser universal", que é, ao mesmo tempo, um "ser específico" único - sobre a natureza.

Além da criação de necessidades, o "processo produtivo de alienação" da sociedade vai gerar, da mesma forma, nas pessoas a busca pela felicidade através da fama, do status social, onde muitos indivíduos procuram a qualquer custo o sucesso de formas muitas vezes condenáveis, totalmente alienadas e individualizadas. A pessoa muitas vezes procura determinados produtos simplesmente para se colocar em um grupo, tribo, ou para ostentar poder em relação a outras pessoas. Pensamos que essa condição de alienação social seja das mais perversas e é uma das mais presentes na sociedade das últimas décadas. 
Mészáros reflete a situação da sociedade na condição de alienados a partir da discussão elaborada por Karl Marx:

(...) é isto que Marx quer dizer - numa sociedade alienada o processo de redução em si mesmo, já que é "inconscientemente" determinado por uma série de necessidades alienadas, está destinado a produzir maior alienação: a sujeição do homem a instrumentos cada vez mais poderosos de sua própria criação." (MÉSZÁROS, p. 98, 2006)

Assim, entendemos que o processo de valorização do consumo proporcionado pelo marketing e pela publicidade atinge uma condição preocupante dentro da sociedade atual, que se deixa alienar pelo ato do consumo e pelo espaço no qual vive, afinal o espaço contribui para a alienação. "O espaço também contribui para o processo de socialização invertida que agora assistimos, e é utilizado como instrumento de política cognitiva, por meio da manipulação do significado, um marketing territorial que também é criador de anomia." (SANTOS, 2007, p. 80)

Tudo isso se torna ainda mais preocupante quando conceitos importantes e fundamentais são acometidos pelas forças capitalistas da publicidade e do marketing, fazendo com que a sustentabilidade, como prática discursiva, reduza-se a um simples argumento de valorização de marcas, ao contrário do que objetiva, que é buscar minimizar desequilíbrios sócios ambientais em todo o ciclo de vida de um produto, inclusive na geração e no descarte de dejetos, o que agrava as consequências da pobreza e desgaste do meio ambiente.

\section{Considerações Finais}

A sociedade e a cultura de consumo pós-moderna estão totalmente intrínsecas, e envolve valores, desejos, hábitos, gostos e necessidades numa escala extremamente intensificada. No contexto pós-moderno, a estetização da vida cotidiana e o triunfo dos signos retratam a subordinação da produção ao consumo sob a forma do marketing, com uma ascensão cada vez maior do conceito de produto, do design e da publicidade.

O modo de produção e de circulação dos bens, os padrões de desigualdade no acesso aos bens materiais e simbólicos, a maneira como se estruturaram as instituições da vida cotidiana, como a família, o lazer, os ambientes urbanos, tudo está relacionado com o consumismo, e nossa sociedade, aculturada pelo consumo, 
constantemente cria e recria novos espaços para os consumidores, tornando o consumo um sistema global que molda as relações dos indivíduos na pós-modernidade e se configura por tecnologias variáveis que determinam os padrões de consumo.

A consequência desse processo que vemos se delinear na sociedade moderna é a criação de uma volatilidade e efemeridade de modas, técnicas de produção, idéias e valores, e no caso específico das mercadorias a ênfase nos valores e virtudes da "instantaneidade" e da "descartabilidade". Ao contrário da "economia da permanência", temos agora a configuração de uma "economia da transitoriedade" que parte do princípio de que é economicamente racional construir objetos baratos, que não podem ser consertados e que sejam descartáveis, ainda que eles possam durar menos. Ao forçar as pessoas a lidarem com a descartalização das coisas, com a novidade e as perspectivas de obsolescência instantânea, a cultura de consumo pós-moderna faz com que a sociedade seja incapaz de organizar coerentemente para o futuro.

O processo capitalista de incentivo a produção, comércio e consumo intensos, faz com que possamos observar gerações de pessoas se perdendo dentro de um sistema de criação de valores e moda que as torna alienadas. Chauí (2000) afirma que existam dois tipos de alienação, primeiramente quando os homens não se reconhecem como agentes e autores da vida social com suas instituições, entretanto, tais indivíduos se acham plenamente livres e capazes de mudar suas vidas individuais da forma que quiserem, independentemente das instituições e condições históricas, ou seja, se colocam ao mesmo tempo, como parte e não parte da sociedade.

Chauí (2000) fala de três grandes formas de alienação nas sociedades capitalistas modernas, a "Alienação Social", a "Alienação Econômica" e a "Alienação Intelectual". A social caracterizando aquele indivíduo passivo para com o que ocorre a sua volta, com as pessoas que necessitam de ajuda, seja ele qual for. A econômica referindo-se a condição de mercadorias na qual o ser humano é tornado a partir do momento que se torna um trabalhador, explorado e manipulado pelas grandes corporações empresariais. Enfim, a intelectual trata do indivíduo que se tem a divisão entre aqueles que produzem mercadorias (trabalho material) e os que produzem ideias (trabalho intelectual), a partir disso há um processo de alienação desde o mais intelectual, até o menos intelectual, que não conseguem viver, de certa forma, harmoniosamente. 
A teoria "alienatória" desenvolvida por Marx, e elaborada por inúmeros autores, procura conceituar as dificuldades e problemas vistos na sociedade atual e intensificados pelo capitalismo e a globalização, de forma que hoje a "Sociedade do Consumo" traga a face mais selvagem desse processo alienatório, seja social, econômico e intelectual.

\section{Referências Bibliográficas}

BARATA SALGUEIRO, T. "Oportunidades e Transformação na cidade centro". Finisterra, XLI, N. 81, 2006.

BAUDRILlARD, J. La Société de Consommation. Paris, Denöel, 1970.

BAUMAN, Z. Modernidade Líquida. Rio de Janeiro, Editora Zahar, 2001.

Vida para o consumo: a transformação das pessoas em mercadoria. São Paulo, Editora Zahar, 2009.

CHAUÍ, M. Convite à Filosofia. São Paulo. Editora Ática, 2000.

HARVEY, D. A Justiça Social e a Cidade. São Paulo. Ed. Hucitec, 1980.

A Condição Pós-Moderna: uma pesquisa sobre as origens da mudança cultural. $18^{\mathrm{a}}$ ed. São Paulo: Ed. Loyola, 2009. 349 p.

HELLER, A. La Revolución de la Vida Cotidiana. Barcelona. Península, 1982.

MÉSZÁROS, I. A Teoria da Alienação em Marx. São Paulo. Editora Boitempo. 2006.

NAVARRO DE BRITO, L. "The Scholl: Education and Alienation". Prospects, 7 (3), p. 337-350. 1972.

PADILHA, V. Shopping Center - a catedral das mercadorias. São Paulo. Editora Boitempo. 2006.

PERROUX, F. Alienation et societé industrielle. Paris, Gallimard. (Collection Idées). 1970.

RODRIGUES, A. M. Produção e consumo do e no espaço. Problemática Ambiental Urbana. São Paulo. Ed. Hucitec. 1998. 
SANTOS, M. O espaço do cidadão. São Paulo. São Paulo, Nobel, 1998.

Por uma outra globalização. $14^{\mathrm{a}}$ edição. Rio de Janeiro. Editora Record.

2007.

Recebido para publicação em junho de 2011

Aprovado para publicação em junho de 2012 